\title{
Selective feeding by sponges on pathogenic microbes: a reassessment of potential for abatement of microbial pollution
}

\author{
Manuel Maldonado ${ }^{1, *}$, Xichang Zhang ${ }^{2,3}$, Xupeng $\mathrm{Cao}^{2}$, Lingyun $\mathrm{Xue}^{2,3}$, \\ Heng $\mathrm{Cao}^{2,3}$, Wei Zhang ${ }^{2,4, * *}$ \\ ${ }^{1}$ Department of Aquatic Ecology, Centro de Estudios Avanzados de Blanes (CSIC), Acceso Cala St. Francesc 14, \\ Blanes 17300, Girona, Spain \\ ${ }^{2}$ Marine Bioproducts Engineering Group, Dalian Institute of Chemical Physics, Chinese Academic of Sciences, \\ Dalian 116023, China \\ ${ }^{3}$ Graduate School of the Chinese Academy of Sciences, Beijing, 10089, China \\ ${ }^{4}$ Flinders Centre for Marine Bioprocessing and Bioproducts, Flinders University, Adelaide, SA 5042, Australia
}

\begin{abstract}
Sponges have traditionally been viewed as rather unselective filter feeders, and therefore as potential biofilters to remediate microbial water pollution. Here we show that the assumed connection between the ability of sponges to feed on microbes and the potential biotechnological use of such an ability to reduce microbial pollution is more complex than assumed. In a laboratory feeding experiment combined with a transmission electron microscopy study, we assessed the potential of the marine sponge Hymeniacidon perlevis to ingest and digest 3 common pathogenic microbes occurring in coastal waters: 2 bacteria (Escherichia coli and Vibrio anguillarum), and 1 marine yeast Rhodotorula sp. All 3 microbes were ingested by the sponge, but selectively, at different rates and following different cellular mechanisms. Yeast cells were processed very atypically by the sponge. Differences in the ingestion and digestion pathways led to large differences in the effectiveness of the sponge to remove the microbes. While sponge grazing reduced the concentration of E. coli and Rhodotorula sp. to levels far below the initial values, sponges were ineffective in abating concentrations of the most infective bacterium, $V$. anguillarum. This bacterium, which was digested more slowly than E. coli, proliferated in the experimental flasks at much higher rates than it was grazed. These findings raise the question whether sponges are suitable for bioremediation of microbial pollution, since selective or preferential ingestion of certain bacteria by sponges may end up fueling growth of those grazed less, such as Vibrio spp.
\end{abstract}

KEY WORDS: Bioremediation · Biofiltration · Bacterivory · Microbial pollution · Yeast digestion Resale or republication not permitted without written consent of the publisher

\section{INTRODUCTION}

Sponges are filter feeders, except for a small family of predatory, carnivorous species. Sponge filter feeding is based on pumping ambient water through an intricate system of aquiferous canals that intersperses the body (see Simpson 1984). Canals are typically lined by pavement-like cells (endopinacocytes) and may form small chambers lined by more columnar, monoflagellated, collar cells (choanocytes). When the seawater flowing through the incurrent canals enters a choanocyte chamber, flow velocity decreases drastically and the suspended particles are deflected towards the microvilli of the choanocytes. This process is facilitated by the currents created by the beating flagellum at the center of each choanocyte microvilli collar. The microvilli collar acts as a sieving basket, retaining particles transiently on its external side until they are subsequently phagocytosed by distal and lateral pseudopodia of the choanocyte. By this mechanism, sponges can retain viruses (e.g. Hadas et al. 2006), bacteria and cyanobacteria (e.g. Reiswig 1971, 
Pile et al. 1996, Pile 1997), as well as larger organisms, including yeast cells, heterotrophic and autotrophic flagellates, diatoms, and ciliates (e.g. Frost 1978, Imsiecke 1993, Pile et al. 1996, Ribes et al. 1999). Nevertheless, the filtering system is rather specialized in retaining picoplankton (size range 0.1 to $2 \mu \mathrm{m}$ ) with maximum efficiency, and somewhat less efficiently nanoplankton (2 to $20 \mu \mathrm{m}$ ), which together provide the bulk of the diet (e.g. Reiswig 1971, 1975, 1990, Pile et al. 1996, Pile 1997, Ribes et al. 1999, Kowalke 2000). There may be also additional incorporation of dissolved and colloidal organic matter (e.g. Stephens \& Schinske 1961, Schmidt 1970, Reiswig 1971, De Goeij et al. 2008), as well as large particles phagocytosed not in the choanocyte chambers, but through the epithelial cells lining the internal aquiferous canals and the sponge surface (e.g. Willenz and Van de Vyver 1984).

Laboratory studies have shown that pathogenic microbes, such as Escherichia coli, Staphylococcus aureus, Klebsiella pneumoniae, Pseudomonas aeruginosa, Vibrio angillarum, and Candida albicans, can be fed to sponges (e.g. Claus et al. 1967, Kunen et al. 1971, Van de Vyver et al. 1990, Milanese et al. 2007, Fu et al. 2006). Laboratory results prompted suggestions that sponges could be integrated in both fish farms and urban waste water discharge systems, so that besides the benefit of rearing sponge biomass for potential biotechnological uses (cosmetics, natural products, aquariophily etc), the cultured sponges would contribute to decreasing bacterial loads in ambient seawater (e.g. Pronzato et al. 1998, Milanese et al. 2003, Fu et al. 2006, Gifford et al. 2007). However, the assumed efficiency of marine sponges to deal with pathogenic bacteria and fungi in a real marine scenario can be deceiving, as this assumption has been derived almost exclusively from feeding experiments using enteric and freshwater microbes. The occurrence of C. albicans, E. coli and other assayed enteric bacteria in coastal waters typically results from terrestrial and freshwater contamination. These non-marine microbes have limited ability to survive and reproduce in seawater and their populations cannot optimally counterbalance grazing by sponges. In contrast, the only available experiment investigating clearance of a marine pathogenic bacterium (Vibrio anguillarum) by sponges found that the bacteria, rather than decreasing in number, proliferated in the experimental aquaria at the 2 concentrations assayed (Fu et al. 2006). Plausible hypotheses are (1) that $V$. anguillarum was reproducing at a higher rate than grazed by the sponges, or (2) that it could infect the sponges during the experiment, causing diminished feeding. The latter hypothesis rests on the idea that sponges can concentrate large quantities of bacteria in their bodies before digestion, favoring their own infection. For instance, Spongia officinalis has been shown to accumulate fecal coliforms, fecal streptococci, and Vibrio sp. from the surrounding ambient water (Kefalas et al. 2003, Stabili et al. 2008). Furthermore, the accumulated bacteria gave rise to viable colonies when homogenates of sponge tissue were cultured in the laboratory, indicating that they were vital and not affected by digestion.

Another issue that potentially flaws some assessments of the potential of marine sponges to deal with pathogenic bacteria is the fact that sponges (and/or their symbiotic microbes) produce a wide spectrum of compounds with antibiotic properties against bacteria and fungi. Diffusion of such compounds from the sponge body to the water of the experimental aquaria could favor a rapid decrease in the concentration of suspended microbes, falsifying estimated clearance and retention rates.

Therefore, before discussing the effectiveness of marine sponges in the abatement of pathogenic microbes, it is necessary to corroborate that marine pathogens are actually digested and that grazing cannot be counterbalanced by microbial reproduction. In the present study 3 pathogenic microbes of both terrestrial and marine origin ( 2 bacteria and 1 yeast) were fed to the marine demosponge Hymeniacidon perlevis (Montagu, 1818). In vitro grazing rates were determined and the fate of the pathogenic cells within the sponge body examined using electron microscopy.

\section{MATERIALS AND METHODS}

Experimental setup. Individuals of the thickly encrusting demosponge Hymeniacidon perlevis were collected (July 24, 2008) from tidal rockpools along the coast of Dalian (Yellow Sea, China), where they may be exposed to air during low tide (Fig. 1a,b). All individuals were acclimated to laboratory conditions for $6 \mathrm{~d}$ in an enclosed system of re-circulating filtered sea water without food addition, which also allowed healing of accidental breakages caused at the basal surface (basopinacoderm) when detaching sponges from rocks by hand. Sponges $(n=66)$ used in the experiment were similar in biomass, averaging $( \pm \mathrm{SD}) 7.01 \pm 1.97 \mathrm{~g}$ wet wt.

About $1 \mathrm{~h}$ before the onset of the experiment, each sponge was transferred to a $500 \mathrm{ml}$ sterile, Erlenmeyer glass flask filled with $400 \mathrm{ml}$ of $0.22 \mu \mathrm{m}$ filtered natural seawater (Fig. 1c,d). We fed sponges using 3 pathogenic microbes that are common in coastal waters: (1) Escherichia coli AS 1.1017 (provided by the Dalian Institute of Light Industry; Fig. 2a), an opportunistic enteric bacteria able to survive transiently in seawater; (2) the marine Vibrio anguillarum II (provided by the Liaoning Institute of Marine Aquaculture Science; Fig. 2b,c), a common pathogen of wild and farmed 


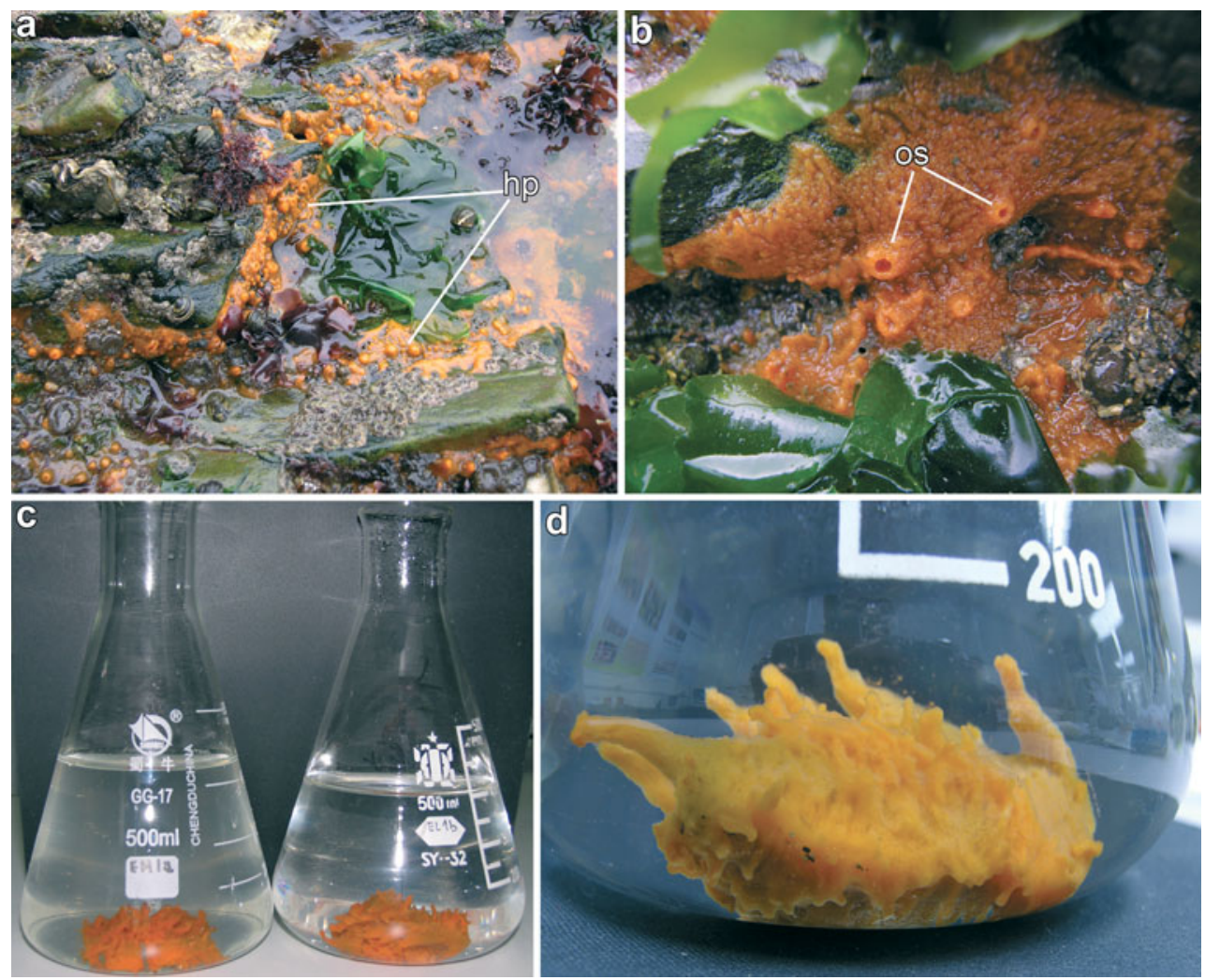

Fig. 1. Hymeniacidon perlevis. (a) Semi-immersed individuals (hp) during low tide at the Dalian coast. (b) Close-up of a specimen completely air-exposed during low tide. Note open oscules (os). (c) Individuals in the experimental Erlenmeyer flasks used for high (left flask) and low (right flask) concentration treatments with Escherichia coli. Note higher seawater turbidity in the flask containing the higher bacterial concentration. (d) Close-up of a sponge after $12 \mathrm{~h}$ in the experimental treatment with high concentrations of Vibrio anguillarum

marine fish, mollusks, and crustaceans (e.g. Myhr et al. 1991); and (3) an undescribed species of red marine yeast belonging to the genus Rhodotorula (purified cultures provided by the Liaoning Institute of Marine Aquaculture Science; Fig. 2d,e), able to produce opportunistic mycoses in vulnerable hosts (e.g. Gyaurgieva et al. 1996, Alliot et al. 2000, Groll \& Walsh 2001). For preparation of E. coli cultures, cells from a single colony grown on agar plate were inoculated into a $250 \mathrm{ml}$ flask containing $100 \mathrm{ml}$ of LB medium (w/v: $0.5 \%$ yeast extract, $1 \%$ peptone, and $1 \% \mathrm{NaCl}$ in distilled water at $\mathrm{pH} 7$ ) and incubated in an orbital shaker at $200 \mathrm{rpm}$ and $37^{\circ} \mathrm{C}$ for $17 \mathrm{~h}$. Cultures of $V$. anguillarum were carried out similarly to those of E. coli, except for use of 2216E medium (w/v: 0.5\% peptone, $0.1 \%$ yeast extract, $0.01 \%$ ferric citrate, and $0.01 \%$ disodium phosphate in seawater at $\mathrm{pH}$ 7.6) and incubation at $28^{\circ} \mathrm{C}$.

About $1 \mathrm{~h}$ after transferring sponges to the flasks, the experiment started by adding aliquots of the previously prepared microbial cultures to the sterile water of the flasks. Each microbe was fed to the sponges at 2 different (hereafter low and high) initial concentra- tions. For the bacterial treatments (i.e., Escherichia coli and Vibrio anguillarum), concentrations were $1 \times 10^{6}$ and $10 \times 10^{6}$ cells $\mathrm{ml}^{-1}$. Given that Rhodotorula cells had an average volume $\left(17.11 \mu^{3}\right)$ about $100 \times$ bigger than that of E. coli $\left(0.16 \mu^{3}\right)$ and $V$. anguillarum $\left(0.39 \mu^{3}\right)$, high and low concentrations of this yeast were calculated to approximate the food/seawater ratio in the flasks to those of the bacterial treatments. Therefore, initial Rhodotorula concentrations were $16 \times 10^{4}$ and $100 \times 10^{4}$ cells $\mathrm{ml}^{-1}$. During the experiment, flasks were continuously agitated $(100 \mathrm{rpm})$ in orbital shakers at room temperature $\left(18^{\circ} \mathrm{C}\right)$. Agitation ensured reoxygenation of seawater in the flasks, compensating for sponge and microbial respiration. It also avoided formation of gradients in microbe concentration, oxygen and excretes. Agitation was thought to facilitate reproduction of microbes, so that bacterial and yeast populations in the flasks had some chances to counterbalance sponge grazing as they would do in field conditions. We decided not to check for potential individual variability in pumping rates during the experiment as the use of water tracers could alter bacterial uptake dynamics in an unpredictable way. 

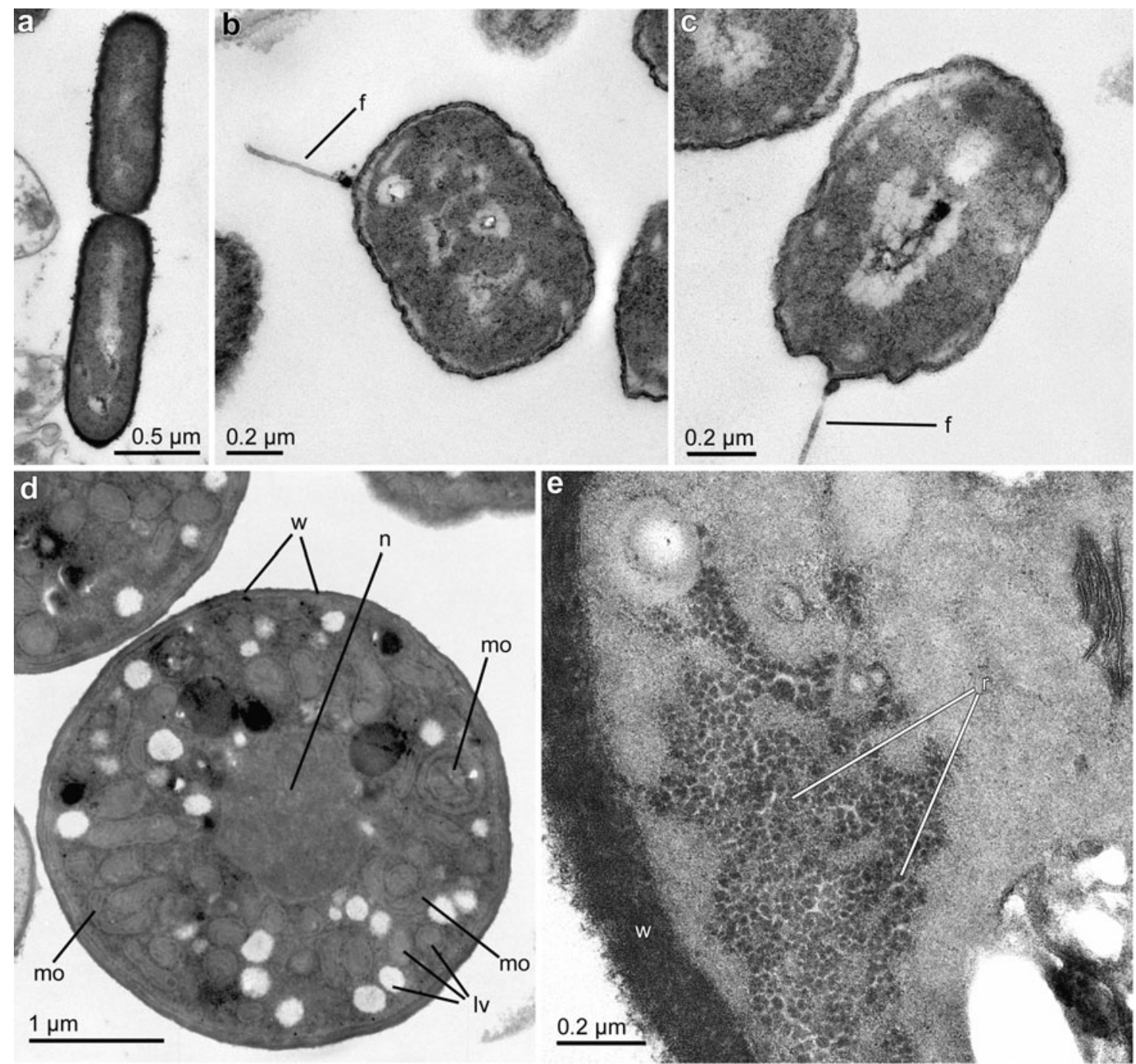

Fig. 2. Electron micrographs of the microbes used for the feeding experiments. (a) Two cells of Escherichia coli AS 1.1017. (b,c) Cells of the flagellated (f) bacterium Vibrio anguillarum II. (d) Rhodotorula sp. cell with a thick chitin wall (w), nucleus (n), lipid vesicles (lv) and multi-membrane organelles (mo). (e) Detail of the yeast cell, showing the cell wall, a dense cytoplasm, and accumulation of putative ribosomes (r)

To assess changes in the concentration of microbes in the flasks over time, we collected an initial, $1 \mathrm{ml}$ sample from each flask immediately upon onset of the experiment, which served as a starting reference (Time $0=12: 00 \mathrm{~h}$ ). Subsequently, flasks were sampled every 4 hours $(16: 00,20: 00$, and 24:00 h) over a total period of $12 \mathrm{~h}$. Each flask sampled for microbial concentration at a given time $(\mathrm{n}=3$ per food treatment, concentration and time level) was removed from the experiment and 2 cubic pieces (about $3 \times 3 \times 3 \mathrm{~mm}$ ) of sponge tissue were excised and fixed for transmission electron microscopy (TEM). We implemented 2 different types of control treatment during the experiment. Sets of flasks that lacked sponges but receiving microbial food at low and high density served as controls for sponge grazing ( $\mathrm{n}=3$ per microbe type, density treat- ment, and time level). An additional set of flasks containing sponges but not receiving microbial food served as controls ( $\mathrm{n}=3$ per time level) for histological observations relative to the ingestion and digestion of microbes by the sponge cells.

Microbe counting. To examine changes in microbial concentrations in the experimental flasks over time, we collected seawater samples $(1 \mathrm{ml})$ at Time $0,4,8$, and 12 , fixed them by adding $34 \%$ formalin $(10 \mu \mathrm{l})$, and subsequently determined microbial concentrations by counting cells using a haemocytometer and a Nikon Eclipse TE2000-U compound microscope. Prior to counting Escherichia coli and Vibrio anguillarum samples, we added polyoxyethylene sorbitan monooleate Tween $80(90 \mu \mathrm{l})$ to prevent cell aggregation, then stained with an additional $100 \mu \mathrm{l}$ of the lipophilic fluo- 
rescenct dye, 1, 1'-dioctadecyl-3,3,3', 3'-tetramethylindocarbocyanine perchlorate, prepared according to manufacturer instructions (Molecular Probes). To complete staining, samples were incubated at $30^{\circ} \mathrm{C}$ for $1 \mathrm{~h}$ in the dark. Cell numbers of $E$. coli and $V$. anguillarum were finally determined on 4 replicates $(0.1 \mu \mathrm{l})$ of each sample. The number of Rhodotorula cells was also determined by haemocytometry but the process did not require previous staining because this yeast is a $3.6 \mu \mathrm{m}$, naturally colored cell which is very obvious under the compound microscope. Increases or decreases in the microbial concentration of each flask for each experimental period $(4,8$, and $12 \mathrm{~h})$ were normalized per hour and gram of dry sponge tissue after freeze-drying and weighing the sponge individuals used in the experiment.

Transmission electron microscopy. Sponge tissue samples were fixed overnight in $2.5 \%$ phosphatebuffered glutaraldehyde, post-fixed in $2 \%$ osmium tetroxide for $1 \mathrm{~h}$, dehydrated in an ethanol-graded series and embedded in Spurr's resin following procedures described elsewhere (Maldonado 2007). Ultrathin sections were studied using a JEOL 1010 transmission electron microscope operating at $80 \mathrm{kV}$ and provided with a Gatan module for acquisition of digital images.

\section{RESULTS}

\section{Dynamics of microbe removal}

Microbial concentrations in the flasks changed over time, following patterns that varied depending on microbe type. Control flasks revealed that Escherichia coli maintained a nearly constant concentration over the experiment, indicating that this bacterium can survive in seawater but is unable to reproduce (Fig. 3a,b). Sponges effectively grazed on both high-density and low-density treatments of E. coli, reducing bacterial concentrations within the experimental flasks by about $60 \%$, irrespective of initial density. The outcome was very different in Vibrio anguillarum flasks. Unlike $E$. coli, control flasks revealed that $V$. anguillarum was able to proliferate rapidly, reaching concentrations by the end of the experiment that were 3 times higher than the initial ones in the high-density flasks and up to 5 times higher in the low-density flasks (Fig. 3a,b). This bacterium even proliferated faster in spongebearing flasks than in control flasks after $8 \mathrm{~h}$ in highdensity treatments (Fig. 3a). Only in the low-density flasks, and after $8 \mathrm{~h}$ of treatment, were sponges able to exert a small,but detectable, grazing effect on the populations of $V$. anguillarum (Fig. 3b). Nevertheless, such grazing was not intense enough to counterbalance

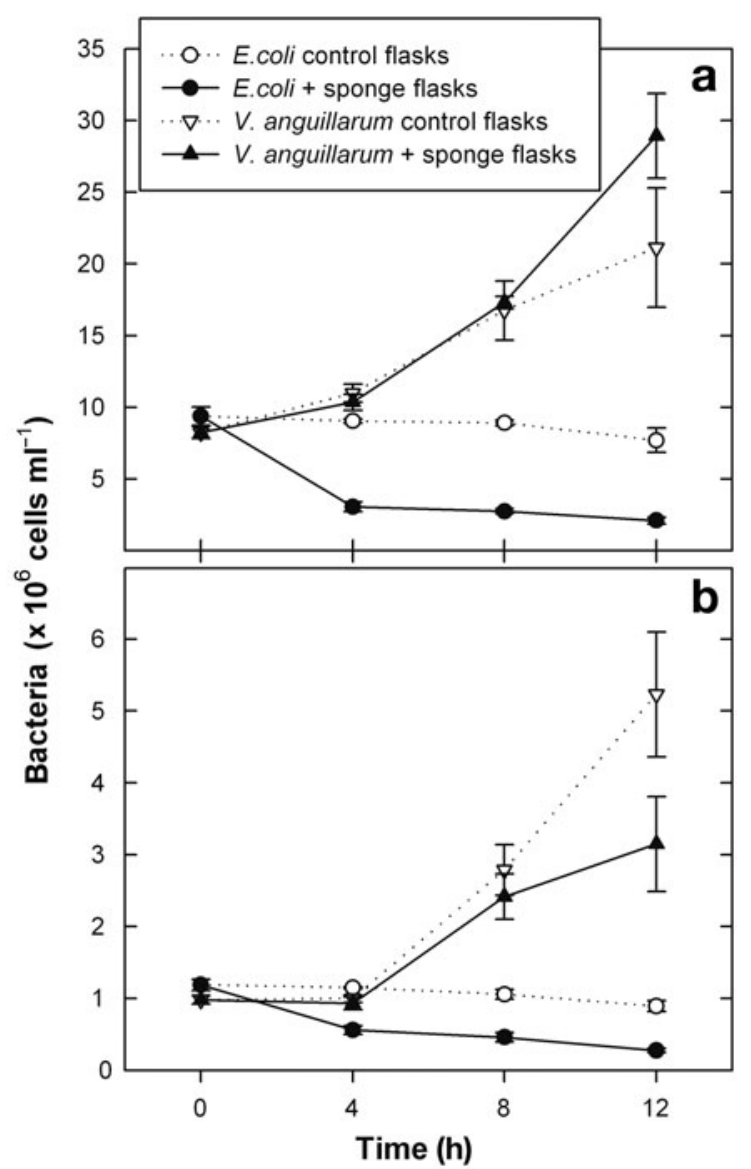

Fig. 3. Escherichia coli and Vibrio anguillarum. Concentration (mean $\pm \mathrm{SD}$ ) over exposure time $(0,4,8$ and $12 \mathrm{~h})$ in highdensity (a) and low-density (b) treatment flasks (with sponges) and control flasks (without sponges)

bacterial proliferation, so that cell concentrations increased progressively in all flasks.

Control flasks of Rhodotorula sp. revealed that yeast concentration decreased in both high-density and lowdensity treatments, with final concentrations being only about $60 \%$ of the initial values (Fig. $4 a$,b). Such dynamics suggested that the yeast was unable to reproduce during the experiment and that some undetermined factor(s) of our experimental setup (e.g. temperature, agitation, light levels, composition of autoclaved seawater, etc) had a moderate deleterious effect on it. In these conditions, sponges caused a substantial decrease (about 75 to $80 \%$ ) of the yeast concentration within both high-density and low-density flasks, with most intense grazing taking place during the first $4 \mathrm{~h}$ (Fig. 4a,b).

When grazing rates were corrected by average microbial decrease (or increase) in the control flasks and normalized per hour and gram of sponge organic dry weight (ODW), some interesting trends emerged (Fig. 5). For Escherichia coli, the grazing rate calcu- 


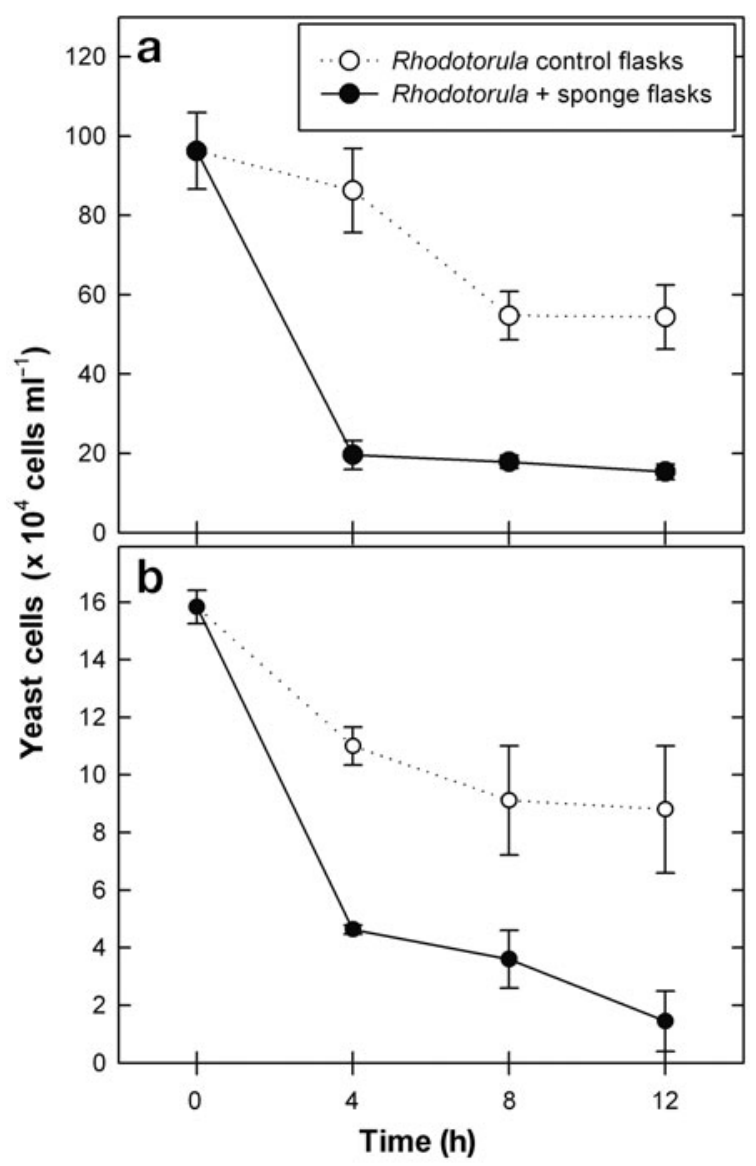

Fig. 4. Rhodotorula sp. Concentration (mean $\pm \mathrm{SD}$ ) over exposure time $(0,4,8$, and $12 \mathrm{~h})$ in the high-density (a) and lowdensity (b) treatment flasks (with sponges) and control flasks (without sponges)

lated for the initial $4 \mathrm{~h}$ period was consistently higher than that after $8 \mathrm{~h}$, which in turn was higher than that after $12 \mathrm{~h}$, irrespective of microbial density. This pattern was nearly opposite to that found for Vibrio anguillarum (Fig. 5). It appears that sponges slowed down grazing rates after an initial period of intense feeding on E. coli, probably to allow digestion of the ingested food before any further massive intake. In contrast, availability of $V$. anguillarum did not stimulate much grazing initially, suggesting that this sponge reluctantly feeds on $V$. anguillarum. Unlike for $E$. coli, grazing on $V$. anguillarum was stimulated only after 8 and $12 \mathrm{~h}$, when concentration of the microbes in the aquaria had grown exponentially (Fig. 5). Such a delayed stimulation of grazing was never sufficient to abate $V$. anguillarum concentrations below the initial experimental values (Fig. 3a,b). Indeed, the aquaria with $V$. anguillarum at high density reached such high bacterial concentrations after $12 \mathrm{~h}$ that grazing rates could not be calculated, with equations yielding strongly negative values for all 3 assayed sponges
(Fig. 5). Higher bacterial densities induced higher grazing rates in most cases, the effects of cell density being most evident when $E$. coli was fed to the sponges. Beyond the initial $4 \mathrm{~h}$ period, the effect of $V$. anguillarum density on grazing was difficult to assess, because proliferation of this bacterium in the experimental flasks became so intense that concentrations in the low-concentration flasks were not 'low' any longer, i.e. not equivalent to those of the $E$. coli treatment (Fig. 3). Grazing on yeast took place at lower rates than those measured for bacteria. Yet the highest yeast concentration appeared to induce slightly higher grazing rates when calculated for the 4 and $12 \mathrm{~h}$ periods.

\section{Histology of microbe intake}

The histological study revealed that choanocyte chambers of Hymeniacidon perlevis are nearly spherical, measuring between 25 and $50 \mu \mathrm{m}$ in lumen diameter (Fig. 6a,b). Choanocytes were slightly amoeboid. Lateral expansions at their basis make them look like an inverted ' $\mathrm{T}$ ' in section. They averaged 3 to $4 \mu \mathrm{m}$ in maximum width and length (Fig. 6a-d). Choanocytes formed a relatively loose cell layer, with conspicuous, non-sealed intercellular spaces (Fig. 6c,d), which do not appear to be a fixation artifact (see 'Discussion'). Control sponges, which remained in the experimental aquaria without bacterial food, showed very few phagosomes in their choanocytes after $4 \mathrm{~h}$ in the experiment (Fig. 6c), probably because previously absorbed food had been either digested (Fig. 6d) or transferred to the underlying amoebocytes (Fig. 6e,f) for subsequent delivery to other mesohyl cells. Choanocytes of sponges fed with Escherichia coli showed only small phagosomes with digested bacterial cells (Fig. 7a), indicating that digestion and assimilation of $E$. coli is a rapid, efficient process. In contrast, digestion of Vibrio anguillarum was more laborious. Choanocytes efficiently phagocytosed V. anguillarum at all times (Fig. $7 \mathrm{~b})$ both in low-density and high-density treatments. However, choanocytes could not complete digestion of this bacterium (Fig. 7c,d). Therefore phagosomes with semi-digested bacteria were transferred to the underlying amoebocytes (Fig. 7b,e,f) for further digestion. The inability of choanocytes to break down $V$. anguillarum cells may account for the low grazing rates measured for this bacterium relative to those measured for E. coli (Fig. 5). We never observed abnormal accumulation or proliferation of $V$. anguillarum within the choanocyte chambers. Likewise, sponges never showed signs of being infected by $V$. anguillarum. Rather, histological sections indicated that these bacteria always occurred in intracellular vacuoles in which they were digested. In both choanocytes and amoebo- 
Fig. 5. Grazing rate (mean $\pm \mathrm{SD}$ ) estimated for the pathogenic microbes in the high-density (HD) and low-density (LD) flasks after standardizing into per gram of dried sponge tissue, hour, and $\mathrm{ml}$ of seawater, and after correcting for control concentrations. Note that hourly grazing rates not only varied with microbe type and density, but also when calculated for periods of different duration $(0,4,8$, and $12 \mathrm{~h})$. Proliferation of Vibrio anguillarum in the high-density treatment was so intense after $12 \mathrm{~h}$ that it overrode any sponge grazing effect, making the calculation of actual grazing rates impossible, which yielded extremely negative values when the formula was applied. E. coli: Escherichia coli; ODW: organic dry weight

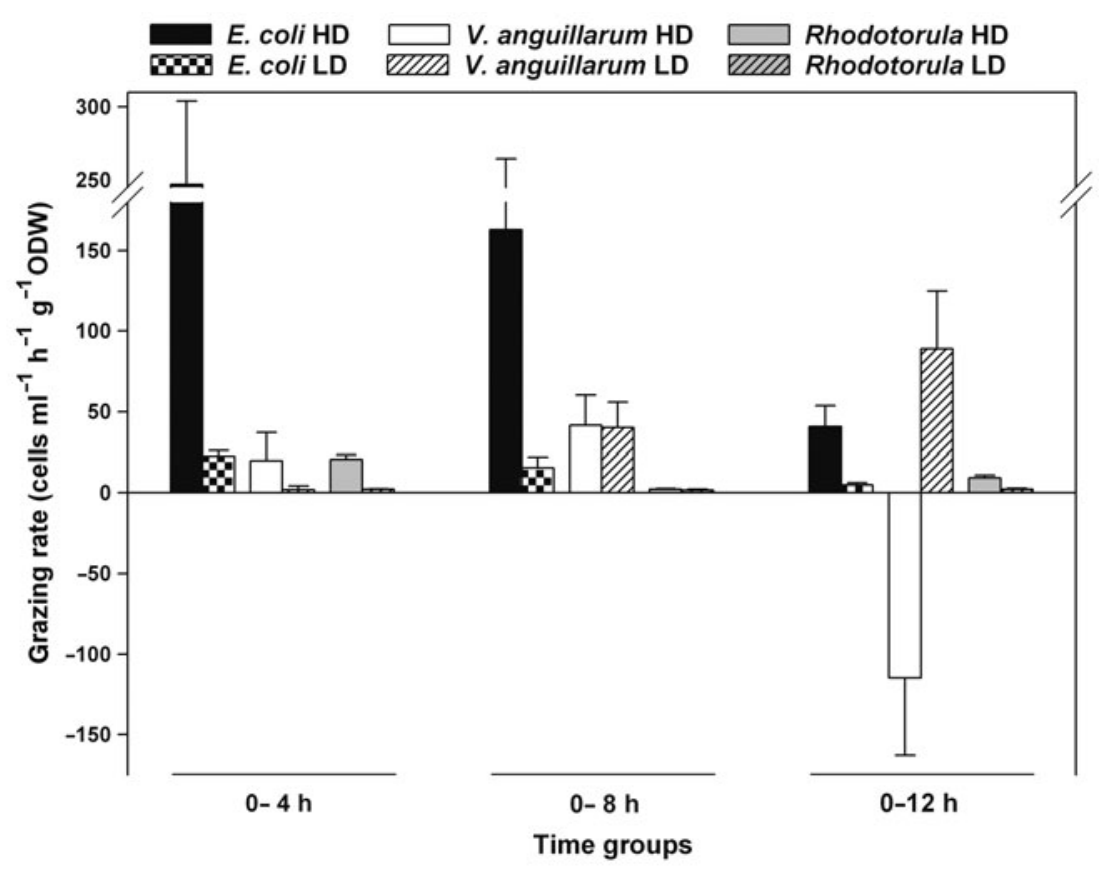

cytes, several $V$. anguillarum cells often appeared together in a single digestive vacuole (Fig. 7b-f).

The TEM study of yeast-fed sponges revealed that Rhodotorula cells often appeared within membranebound vesicles in the amoebocytes that surround the choanocyte chambers but never within the choanocytes (Fig. 8a-d). These observations strongly suggested that choanocytes were unable to phagocytose Rhodotorula cells. This is not surprising, since yeast cells ( 3 to $4 \mu \mathrm{m}$ in diameter) were nearly as large as the choanocytes themselves (Fig. 8a-c). In contrast, amoebocytes typically measured 10 to $20 \mu \mathrm{m}$, and were able to engulf up to 2 yeast cells (Fig. 8d-f). Within the amoebocytes, yeasts showed distortion, shrinkage, wall dissolution and lysis as signs of being digested (Fig. 8d-f). Given that choanocytes did not capture yeast cells, the question arose how these cells entered the cytoplasm of amoebocytes. We noticed that amoebocytes were able to engulf yeast cells directly from the chambers after transiently leaving the mesohyl to enter the choanocyte chambers through the wide intercellular spaces between choanocytes (Fig. 9a-c). Additionally, small groups of undigested yeast cells were seen intercellularly in the mesohyl adjacent to the choanocyte chambers (Fig. 9c,e). It is likely that choanocytes allowed yeast cells to enter the mesohyl (see 'Discussion'), probably by regulating the width of the intercellular spaces in the choanocyte chamber. The yeasts that occurred intercellularly in the mesohyl never showed signs of infecting the sponge. Rather, histological sections suggested that they were rapidly surrounded by aggregating amoebocytes (Fig. 9d,f), probably to be engulfed afterwards.
Yeast cells were also phagocytosed directly from the seawater by the epithelial cells (endopinacocytes) lining the walls of the aquiferous canals (Fig. 10a-c). In the mesohyl, pinacocyte-like cells occur which are charged with yeast cells (Fig. 10d). This suggested that endopinacocytes, after phagocytosis of yeast cells, migrated into the mesohyl either to complete digestion or to transfer the collected yeast to other cells. Interestingly, there were several instances of large amoebocytes phagocytosing yeast cells that had previously been phagocytosed by another sponge cell (Fig. 10e,f). The appearance of the inner, thin cytoplasmic band around these twice-phagocytosed yeasts suggested that the former cell bearing the yeast could be an endopinacocyte.

\section{DISCUSSION}

Since Van Weel (1949) and Kilian (1952) confirmed that particles smaller than approximately $5 \mu \mathrm{m}$ are ingested mostly by choanocytes while larger particles are ingested by the cells of the internal and external epithelia (endopinacocytes and exopinacocytes, respectively), the question whether sponges are able to discriminate food particles according to features other than size has hardly been asked. However, a few studies have clearly demonstrated that at least some sponges may perform a size-independent selection of the ingested microbes (e.g. Frost 1976, 1980b, Van de Vyver et al. 1990, Yahel et al. 2006, Wehrl et al. 2007). Likewise, the outcome of our experiment supports that feeding in Hymeniacidon perlevis is a selective process. 

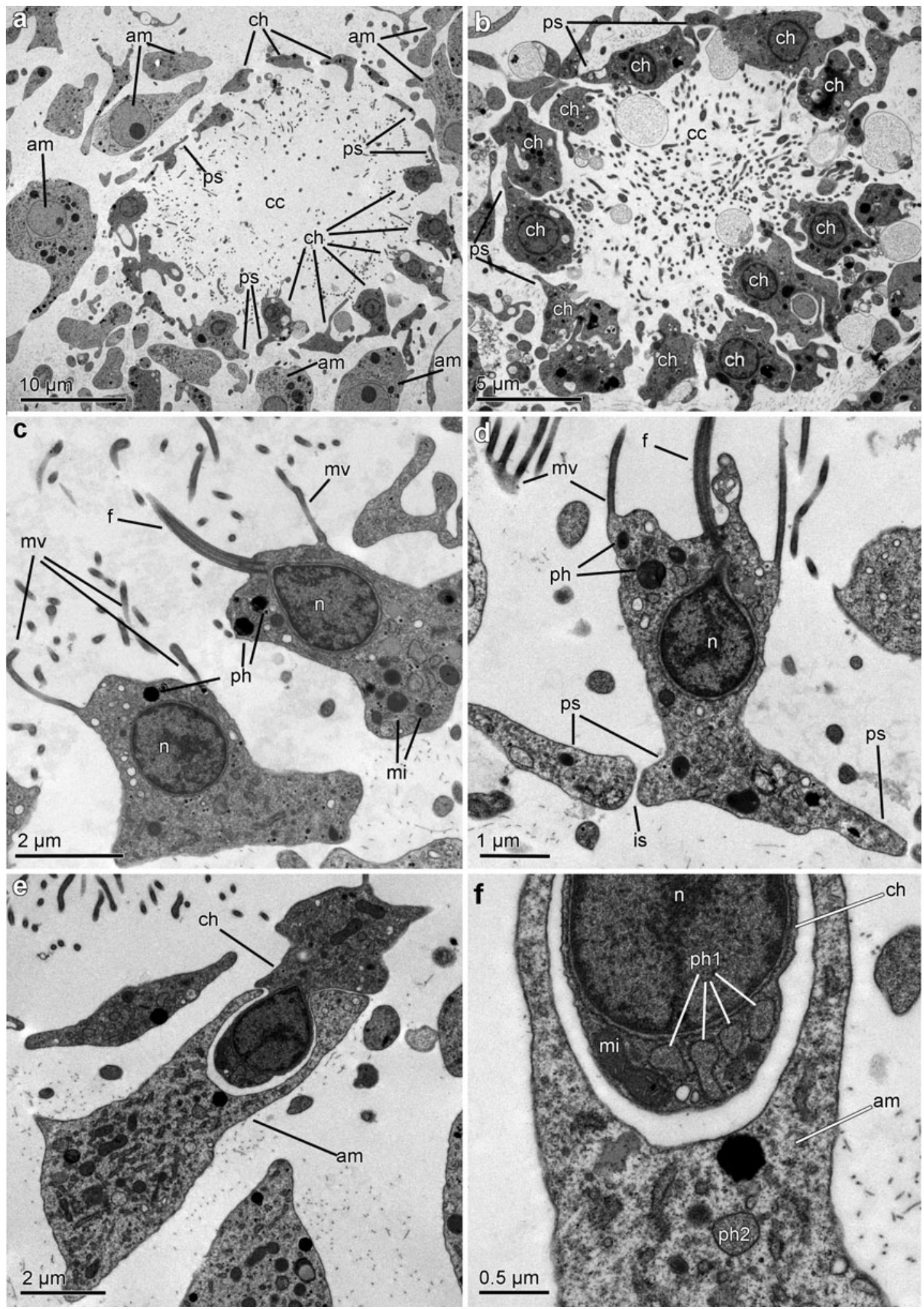

Fig. 6. Hymeniacidon perlevis. Choanocyte traits. (a,b) Subspherical choanocyte chambers (cc), with ample spaces between the choanocytes (ch), which contact each other by means of lateral pseudopodida (ps). Large amebocytes (am) are located immediately below the choanocytes to gather the phagosomes transferred from the choanocytes. (c) Longitudinal section of choanocyte in a control sponge after $4 \mathrm{~h}$, showing very few and small phagosomes (ph). Note the flagellum (f), the microvilli of the collar (mv), the nucleus (n), and some mitochondria (mi). (d) Detail of choanocyte showing the typical inverted-T shape due to occurrence of basal-lateral expansion (ps), which probably regulate the width of the intercellular spaces (is). (e) Amoebocyte enveloping the basal portion of a choanocyte in a control sponge after $12 \mathrm{~h}$ without food, probably in an attempt to collect phagosomes potentially extruded by the choanocyte. (f) Detail of the basal region of the choanocyte surrounded by the amebocyte in (e). The choanocyte shows part of the nucleus, a mitochondrium, and several vesicles that appear to be phagosomes with highly digested contents 


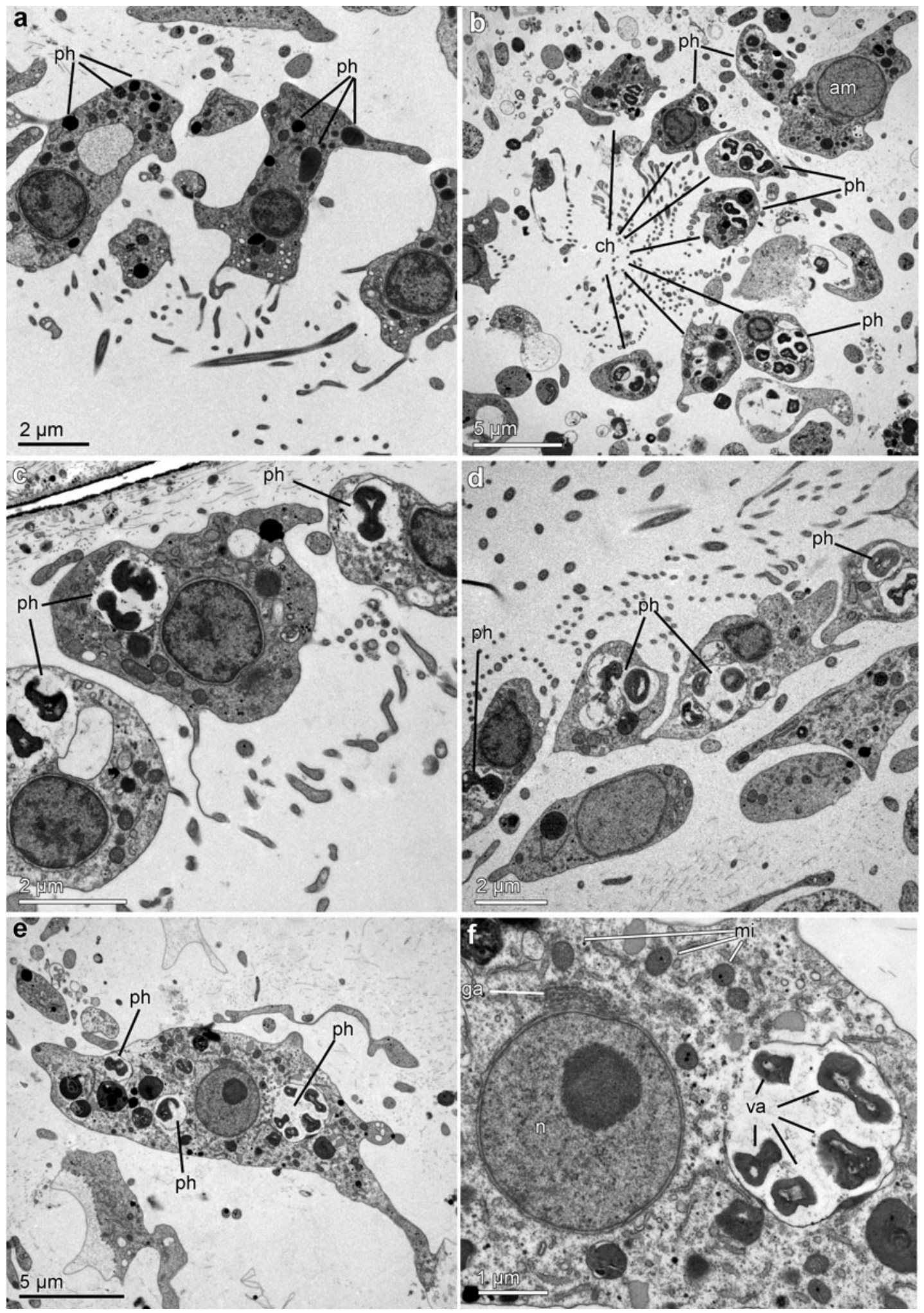

Fig. 7. Hymeniacidon perlevis. Digestion stages of pathogenic bacteria. (a) Choanocytes of a sponge after $4 \mathrm{~h}$ in the high-density treatment of Escherichia coli, showing that all phagocytosed bacteria are deeply digested in small phagosomes (ph). (b) Choanocyte chamber of a sponge after $8 \mathrm{~h}$ in the high-density treatment of Vibrio anguillarum, showing that Vibrio cells are semi-digested in phagosomes both in choanocytes (ch) and the underlying amoebocytes (am). (c,d) Details of choanocytes of sponges feeding in high density of $V$. anguillarum for 8 and $12 \mathrm{~h}$, respectively. Phagosomes contain one to several bacterial cells, which are consistently half digested. (e) Amoebocyte with phagosomes containing semi-digested Vibrio cells. (f) Detail of cell in (e), showing the nucleus (n) of the amoebocyte, the Golgi apparatus (ga), several mitochondria (mi) and a phagosome with digested $V$. anguillarum cells (va) 


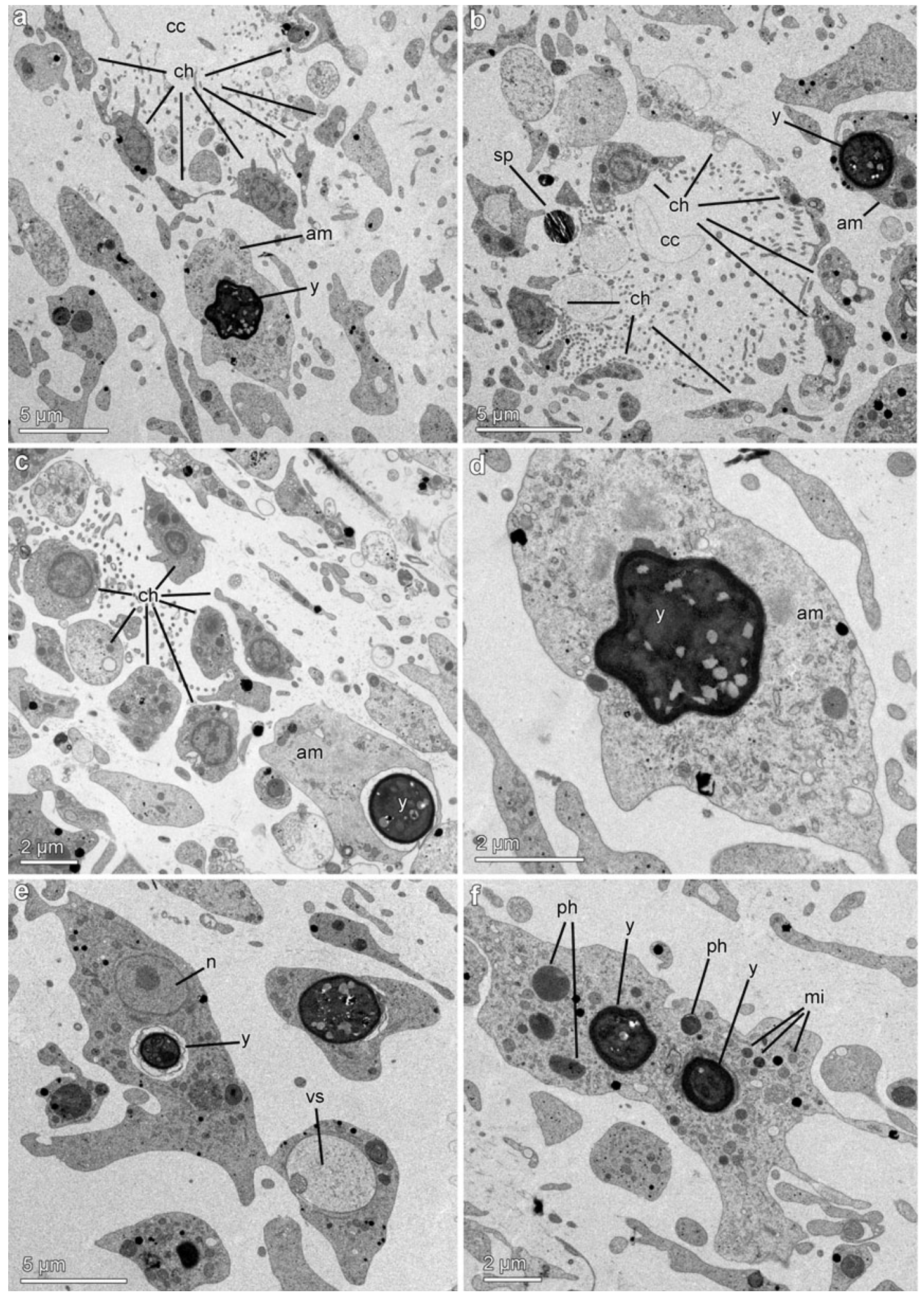

Fig. 8. Hymeniacidon perlevis. Intake and digestion of yeast cells. (a-c) Choanocyte chamber (cc) of a sponge after $4 \mathrm{~h}$ in a flask with high density of Rhodotorula cells. Typically, choanocytes (ch) did not show phagocytosed yeast cells, whereas yeast cells (y) often occurred within the amoebocytes (am) adjacent to the choanocyte chambers. Note a spicule (sp) in the vicinity of the choanocyte chamber. (d) Enlargement of (a) showing distortion of the yeast cell as a result of beginning the digestive process within the amoebocyte vacuole. (e) Lobate archaeocyte/amoebocyte showing a nucleus (n), a large electron-lucent vesicle (vs), and a phagocytosed yeast cell. (f) Large amoebocyte with 2 phagocytosed yeast cells, several small phagosomes (ph) and many mitochondria (mi) 

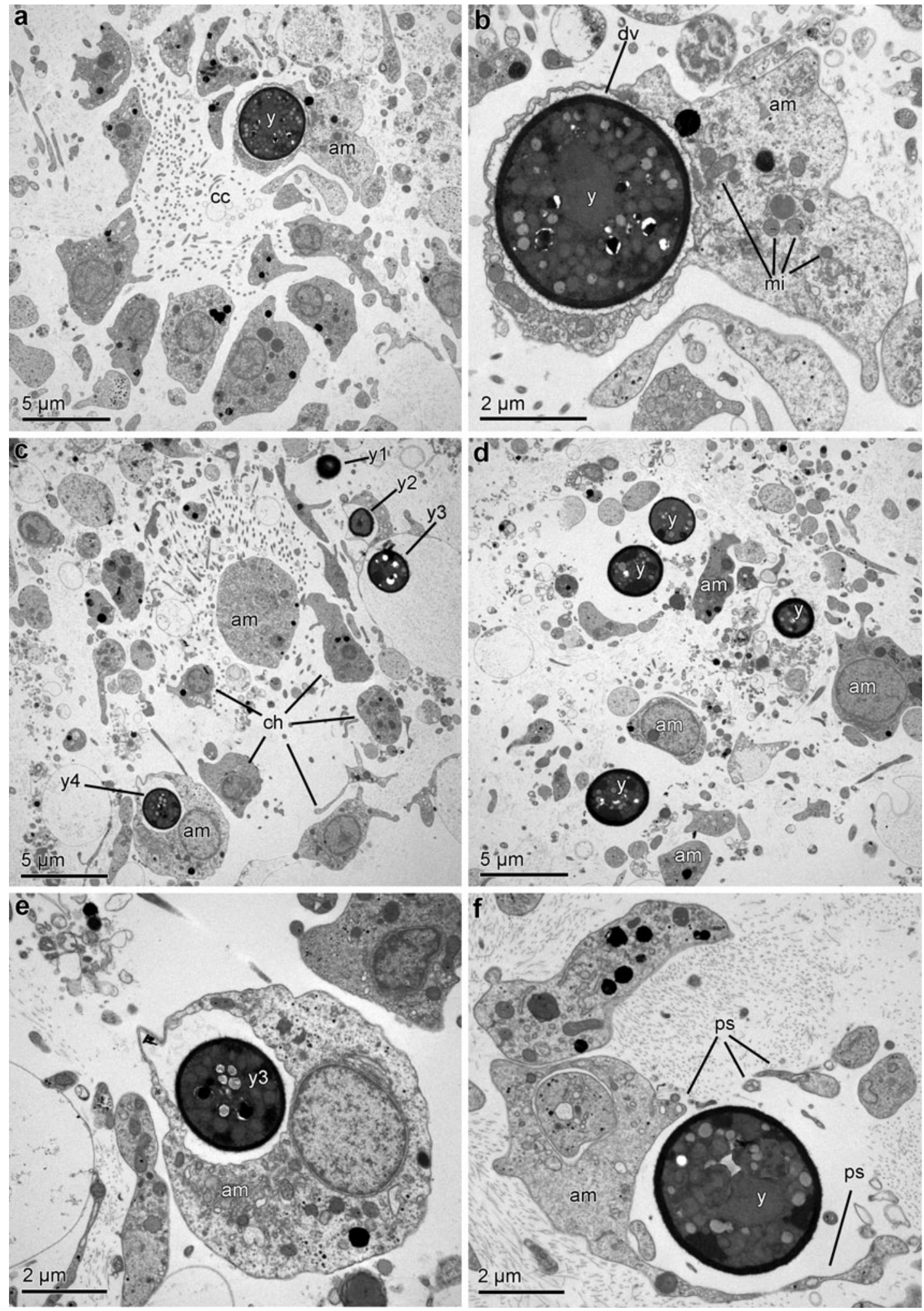

Fig. 9. Hymeniacidon perlevis. Phagocytosis of yeast cells by amoebocytes. (a) Large amoebocyte (am) that entered a choanocyte chamber (cc) to phagocytose a yeast cell (y). (b) Enlargment of the amoebocyte in (a) showing the membrane-bound digestive vacuole (dv) with a yeast cell, and many mitochondria (mi). (c) Choanocyte chamber with a large amoebocyte in its lumen. Note size difference between choanocytes (ch) and the amoebocyte. An intercellular yeast cell (y1) can be seen in the mesohyl adjacent to the chamber. An amoebocyte nearby has phagocytosed a yeast cell (y3) into a large vesicle and is about to engulf a second cell (y2). On the other side of the chamber, another amoebocyte has also phagocytosed a yeast cell (y4). (d) Several undigested yeast cells lying free in the sponge mesohyl close to a choanocyte chamber. Note several amoebocytes aggregated in this area for probable yeast phagocytosis. (e) Enlargement of (c) showing an amoebocyte with a phagocytosed yeast cell.

(f) Amoebocyte with pseudopodia (ps) surrounding a yeast cell (y) 

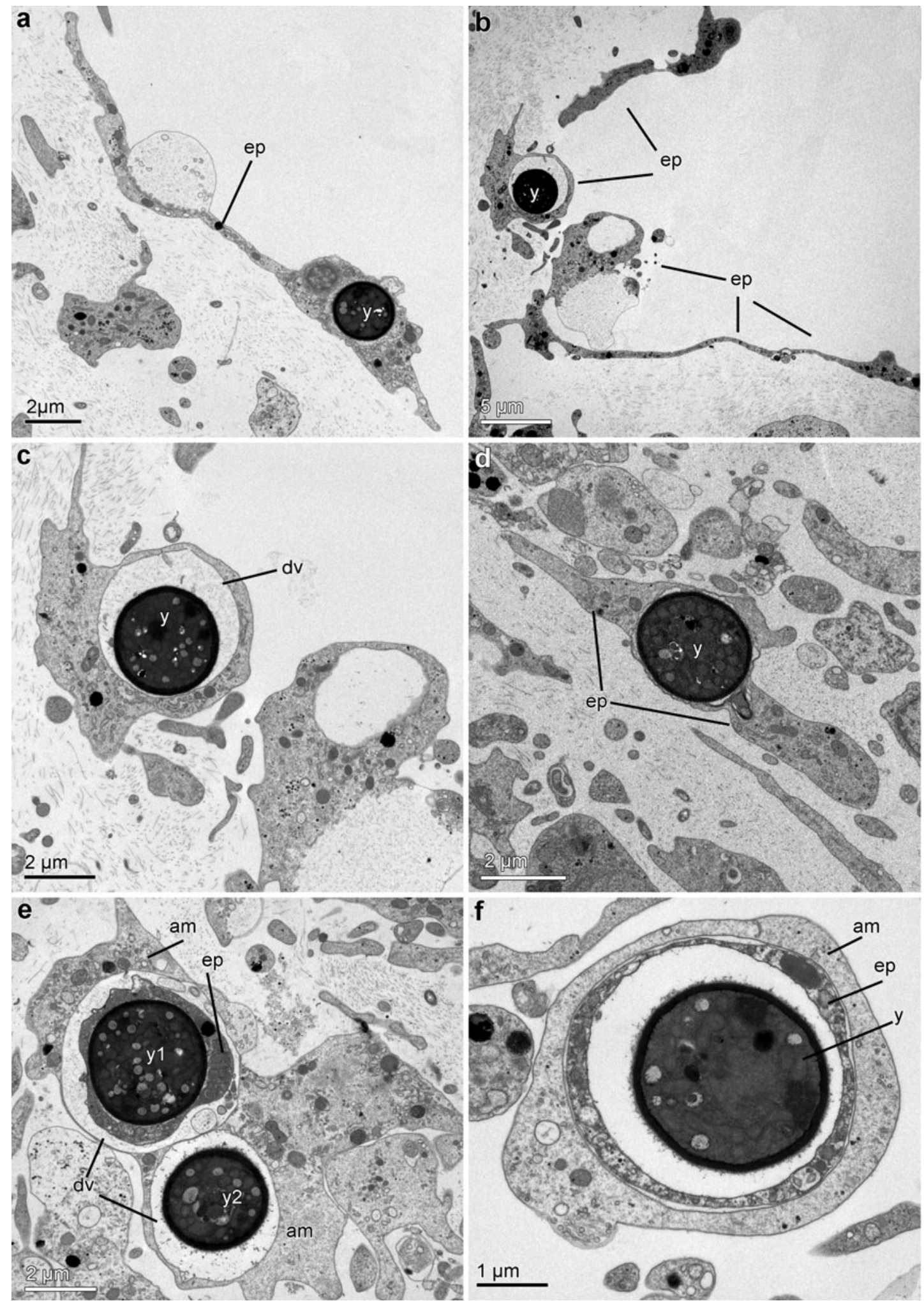

Fig. 10. Hymeniacidon perlevis. Phagocytosis of yeast cells by pinacocytes. (a,b) Endopinacocytes (ep) with phagocytosed yeast cells (y). (c) Enlargement of endopinacoyte in (a), showing that the yeast cell is kept within a membrane-bound digestive vacuole (dv). (d) View of a putative endopinacocyte that has phagocytosed a yeast cell and left the epithelium to enter the mesohyl. (e) View of a large amoebocyte (am) with 2 yeast cells (y1, y2) in membrane-bound vesicles. Note that one of the yeast cells (y1) has been previously phagocytosed by another sponge cell (ep), probably an endopinacocyte. (f) Detail of another amoebocyte showing a phagocytosed yeast that has previously been engulfed by another sponge cell (ep) 
Normalized grazing rates calculated for a $4 \mathrm{~h}$ period clearly showed that grazing was more effective on Escherichia coli than on Vibrio anguillarum at both high and low cell density. A similar result was obtained for grazing rates calculated through an $8 \mathrm{~h}$ period, with the exception that in this case the 'low-density' food treatment of $V$. anguillarum was outgrown by the the nearly exponential bacterial proliferation (Fig. 3b). Because size differences between E. coli $(0.4 \times 1 \mu \mathrm{m})$ and $V$. anguillarum $(0.6 \times 1.1 \mu \mathrm{m})$ are minimal, the substantial differences found between their respective grazing rates must be explained by the sponge being able to readjust the intake rate of each bacterium in response to features other than size. Digesting $V$. anguillarum appeared to be a more laborious process than digesting E. coli. This may also have accounted for differences in grazing rate. The demonstrated ability of at least some sponge species to selectively intake 'food particles' by features other than size advises caution when using polystyrene, latex beads and other artificial, inert materials to investigate retention and clearance rates as well as to trace ingestion and digestion pathways.

The mechanism used by sponges to qualitatively discriminate between bacteria remains enigmatic. In the case of Vibrio anguillarum, the occurrence of a flagellum, which is likely to be beating within the choanocyte chambers during the process of phagocytosis, might well complicate the engulfing by the choanocytes. However, Wehrl et al. (2007) reported that retentions rates of hyperflagellated and hypoflagellated Vibrio mutants were similar to that of the respective wild-type strain. Therefore, it has to be considered that choanocytes are actually able to discriminate bacteria by perceiving characteristic wall compounds, as suggested by Wehrl et al. (2007). Not surprisingly, choanocytes are long known to be able to identify conspecific spermatozoa among the many particles that the inflow takes to the choanocyte chambers. They selectively ingest spermatozoa in a special vacuole that, unlike bacterium-containing vacuoles, skips digestion and is finally transferred to the oocyte for eventual fertilization (e.g. Gatenby 1920, Tuzet \& Pavans de Ceccatty 1958, Nakamura \& Okada 1998, Riesgo et al. 2007). Whatever the discriminating mechanism, the fact that sponges can distinguish between different microbes at ingestion is of major importance in terms of their potential application for bioremediation. If sponges that are deployed to reduce microbial pollution start grazing more effectively on some non-pathogenic bacteria than on alternative pathogenic microbes such as $V$. anguillarum, this may end in facilitating proliferation of the pathogenic forms and aggravating, rather than mitigating, the problem.
Our experiments also revealed that grazing rates by Hymeniacidon perlevis were dependent on microbe concentration. Although many studies have found that grazing and retention rates are independent of food concentration (e.g. Reiswig 1971, 1975, Frost 1978, 1980a,b, Wehrl et al. 2007), our results are consistent with a previous study on $H$. perlevis, which also showed a significant effect of bacterial concentration on the sponge grazing rate (Fu et al. 2006). The diversity in the outcome of different studies suggests that sponge feeding cannot be properly explained by a merely mechanistic filtration model and that a wide array of situations appear to occur, depending on the specific food organism and the sponge species. It is also noteworthy that grazing rates in our experiment were higher when calculated over a $4 \mathrm{~h}$ period than over 8 or $12 \mathrm{~h}$. Most probably, sponges were continuously pumping water and retaining most food particles for the first few hours (i.e. $4 \mathrm{~h}$ ) after the initial food pulse. Then, at some point, they started alternating periods of high and low retention (or pumping activity) to allow choanocytes and adjacent amoebocytes to process the ingested material. Nevertheless, the fact that we never found accumulation of microbes in the choanocyte chambers (not even after very high bacterial densities were reached in the flasks containing Vibrio sp.) suggests that sponges were pumping water almost continuously during the experiment, irrespective of food retention. Under conditions of food oversupply, continuous pumping may be required to prevent clogging of choanocyte chambers, to maintain oxygen supply and to facilitate shedding of egested materials and excretes.

Yeast cells were grazed at lower rates than bacteria during the experiment, particularly in the high-density treatment. This is in good agreement with several previous studies also using large Rhodotorula cells as sponge food (e.g. Frost 1978, 1980a). Those low grazing rates were probably caused by choanocytes of Hymeniacidon perlevis being unable to phagocytose yeast cells, so that alternative pathways have to be used for ingestion and digestion. We noticed 3 different mechanisms for yeast processing: (1) ingestion by endopinacocytes of the incurrent canals; (2) ingestion by amoebocytes that entered the choanocyte chambers; and (3) direct transit of yeast cells from the choanocyte chambers to the adjacent mesohyl through intercellular spaces between choanocytes. All 3 mechanisms had previously been noticed at some level by different authors (see below). It is long known that the endopinacocytes of the incurrent canals are able to engulf yeast cells, microalgae, and latex beads larger than 4 to $5 \mu \mathrm{m}$ (reviewed by Simpson 1984). More surprising was our finding that amoebocytes can enter the choanocyte chambers of $H$. perlevis. Nevertheless, 
there were also reports that amoebocyte-like cells are able to enter the incurrent canals to engulf large particles (Minchin 1900, Kilian 1952); amoebocytes can also enter the spermatic cysts to 'predate' on developing spermatocytes and to remove waste spermatozoa (Riesgo et al. 2008). The direct transfer of particles from the choanocyte chambers to the adjacent mesohyl through intercellular spaces is another unconventional pathway that we noticed and that has seldom been reported in the literature. Nevertheless, intercellular spaces between choanocytes have been described in many sponges (e.g. Langenbruch 1988). Openings also occur in the epithelium of the incurrent canals, facilitating the wandering of mesohyl cells back and forth into the canals, as well as the transfer of large food particles from the canals to the mesohyl (Weissenfels 1975, 1976, De Vos 1979, Simpson 1984). We discovered an additional unconventional pathway for yeast digestion, which, to our knowledge, has not been previously described for sponges. We found several instances (Fig. 10e,f) of large amoebocytes having phagocytosed another entire sponge cell (putatively an endopinacocyte) that had previously engulfed the yeast cell.

In summary, our findings strongly support the emerging view that retention, ingestion, and digestion of microbial food are complex processes that may notably vary between sponge species, and also be dependant on the nature, size and concentration of food particles. We suggest that, before deciding on the use of a particular sponge species as a biofilter to abate microbial pollution in marine environments, preliminary tests should establish that the sponge candidate effectively feeds on the microbial targets and does not select against any relevant pathogenic species.

Acknowledgements. The authors thank the Dalian Institute of Light Industry and the Liaoning Institute of Marine Aquaculture Science for providing cultures of the assayed pathogens. We also thank A. García and N. Cortadellas (Electron Microscopy Service of the University of Barcelona) for help with sample processing for electron microscopy. This research was funded by a MYCT grant (BFU2008-00227/BMC), a grant for bilateral cooperation between the Spanish CSIC and the Chinese Academy of Sciences, and funds from the 'Hi-Tech Research and Development Program of China' (2006AA09Z435).

\section{LITERATURE CITED}

Alliot C, Desablens B, Garidi R, Tabuteau S (2000) Opportunistic infection with Rhodotorula in cancer patients treated by chemotherapy: 2 case reports. Clin Oncol 12: $115-117$

Claus G, Madri P, Kunen S (1967) Removal of microbial pollutants from waste effluents by the redbeard sponge. Nature 216:712-714

De Goeij JM, Van de Berg H, Van Oostveen M, Epping EHG, Van Duyl FC (2008) Major bulk dissolved organic carbon (DOC) removal by encrusting coral reef cavity sponges.
Mar Ecol Prog Ser 357:139-151

De Vos L (1979) Structure tridimensionelle de l'éponge Ephydatia fluviatilis. In: Lévi C, Boury-Esnault N (eds) Biologie des Spongiaires. C.N.R.S., Paris, p 159-164

Frost TM (1976) Sponge feeding: a review with a discussion of some continuing research. In: Harrison FW, Cowden RR (eds) Aspects of sponge biology. Academic Press, New York, p 283-298

Frost TM (1978) In situ measurement of clearance rates for the freshwater sponge Spongilla lacustris. Limnol Oceanogr 23:1034-1039

Frost TM (1980a) Clearance rate determinations for the freshwater sponge Spongilla lacustris. Effect of temperature, particle type and concentration, and sponge size. Arch Hydrobiol 90:330-356

Frost TM (1980b) Selection in sponge feeding processes. In: Smith DC, Tiffon Y (eds) Nutrition in the lower Metazoa. Pergamon Press, Oxford, p 33-44

Fu W, Sun LM, Zhang XC, Zhang W (2006) Potential of the marine sponge Hymeniacidon perleve as a bioremediator of pathogenic bacteria in integrated aquaculture ecosystems. Biotechnol Bioeng 93:1112-1122

> Gatenby JB (1920) The germ-cells, fertilization and early development of Grantia (Sycon) compressa. J Linnean Soc Lon Zool 34:261-297

Gifford S, Dunstan RH, O'Connor W, Koller CE, MacFarlane GR (2007) Aquatic zooremediation: deploying animals to remediate contaminated aquatic environments. Trends Biotechnol 25:60-65

Groll AH, Walsh TJ (2001) Uncommon opportunistic fungi: new nosocomial threats. Clin Microbiol Infect 7:8-24

Gyaurgieva OH, Bogomolova TS, Gorshkova GI (1996) Meningitis caused by Rhodotorula rubra in an HIVinfected patient. J Med Vet Mycol 34:357-359

Hadas E, Marie D, Shpigel M, Ilan M (2006) Virus predation by sponges is a new nutrient-flow pathway in coral reef food webs. Limnol Oceanogr 51:1458-1550

> Imsiecke G (1993) Ingestion, digestion, and egestion in Spongilla lacustris (Porifera, Spongillidae) after pulse feeding with Chlamydomonas reinhardtii (Volvocales). Zoomorphology 113:233-244

Kefalas E, Castritsi-Catharios J, Miliou H (2003) Bacteria associated with the sponge Spongia officinalis as indicators of contamination. Ecol Indic 2:339-343

- Kilian EF (1952) Wasserströmung und Nahrungsaufnahme beim Süßwasserschwamm Ephydatia fluviatilis. Z Vgl Physiol 34:407-447

- Kowalke J (2000) Ecology and energetics of two Antarctic sponges. J Exp Mar Biol Ecol 247:85-97

Kunen S, Claus G, Madri P, Peyser L (1971) The ingestion and digestion of yeast-like fungi by the sponge, Microciona prolifera. Hydrobiologia 38:565-576

Langenbruch PF (1988) Body structure of marine sponges. V. Structure of choanocytes chambers in some Mediterranean and Caribbean haplosclerid sponges (Porifera). Zoomorphology 108:13-21

Maldonado M (2007) Intergenerational transmission of symbiotic bacteria in oviparous and viviparous demosponges, with emphasis on intracytoplasmically-compartmented bacterial types. J Mar Biol Assoc UK 87:1701-1713

> Milanese M, Chelossi E, Manconi R, Sarà A, Sidri M, Pronzato R (2003) The marine sponge Chondrilla nucula Schmidt, 1862 as an elective candidate for bioremediation in integrated aquaculture. Biomol Eng 20:363-368

Minchin EA (1900) The Porifera and Coelenterata. In: Lakenster R (ed) Treatise on zoology, Vol 2. A. \& Ch. Black, London, p 1-178 
Myhr E, Larsen JL, Lillehaug A, Gudding R, Heum M, Hastein T (1991) Characterization of Vibrio anguillarum and closely related species isolated from farmed fish in Norway. Appl Environ Microbiol 57:2750-2757

Nakamura Y, Okada K (1998) The ultrastructure of spermatozoa and its structural change in the choanocytes of Sycon calcaravis Hozawa. In: Watanabe Y, Fusetani N (eds) Sponge sciences: multidisciplinary perspectives. Springer, Tokyo, p 179-191

Pile AJ (1997) Finding Reiswig's missing carbon: quantification of sponge feeding using dual-beam flow cytometry. Proc 8th Int Coral Reef Symp 2:1403-1410

Pile AJ, Patterson MR, Witman JD (1996) In situ grazing on plankton $<10 \mu \mathrm{m}$ by the boreal sponge Mycale lingua. Mar Ecol Prog Ser 141:95-102

Pronzato R, Cerrano C, Cubeddu T, Lanza S and others (1998) Sustainable development in coastal areas: role of sponge farming in integrated aquaculture. In: Grizel H, Kesmont $\mathrm{P}$ (eds) Aquaculture and water: fish culture, shellfish culture and water usage. Special publication no. 26. European Aquaculture Society, Bourdeaux, p 231-232

Reiswig HM (1971) Particle feeding in natural populations of 3 marine demosponges. Biol Bull 141:568-591

Reiswig HM (1975) Bacteria as food for temperate-water marine sponges. Can J Zool 53:582-589

Reiswig HM (1990) In situ feeding in 2 shallow-water hexactinellid sponges. In: Rützler K (ed) New Perspectives in Sponge Biology. Smithsonian Institution Press, Washington, DC, p 504-510

Ribes M, Coma R, Gili JM (1999) Natural diet and grazing rate of the temperate sponge Dysidea avara (Demospongiae, Dendroceratida) throughout an annual cycle. Mar Ecol Prog Ser 176:179-190

Riesgo A, Maldonado M, Durfort M (2007) Dynamics of gametogenesis, embryogenesis, and larval release in a Mediterranean homosclerophorid demosponge. Mar Freshw Res 58:398-417

Riesgo A, Maldonado M, Durfort M (2008) Occurrence of somatic cells within the spermatic cysts of demosponges: A discussion of their role. Tissue Cell 40:387-396

Schmidt I (1970) Phagocytose et pincytose chez les Spongilli-

Editorial responsibility: Joseph Pawlik, Wilmington, North Carolina, USA dae. Etude in vivo de l'ingestion de bactéries et de protéines marquées à l'aide d'un colorant fluorescent en lumière ultra-violette. Z Vgl Physiol 66:398-420

Simpson TL (1984) The cell biology of sponges. SpringerVerlag, New York

Stabili L, Licciano M, Longo C, Corriero G, Mercurio M (2008) Evaluation of microbial accumulation capability of the commercial sponge Spongia officinalis var. adriatica (Schmidt) (Porifera, Demospongiae). Water Res 42: 2499-2506

Stephens GC, Schinske RA (1961) Uptake of amino acids by marine invertebrates. Limnol Oceanogr 6:175-181

Tuzet O, Pavans de Ceccatty M (1958) La spermatogenèse, l'ovogenèse, la fécondation et les premiers stades du développement chez Octavella galangaui. Vie Milieu 115:309-327

Van de Vyver G, Vray B, Belaouane S, Toussaint D (1990) Efficiency and selectivity of microorganism retention by Ephydatia fluviatilis. In: Rützler K (ed) New perspectives in sponge biology. Smithsonian Institution Press, Washington, DC, p 511-515

Van Weel PB (1949) On the physiology of the tropical freshwater sponge Spongilla proliferans (Annandale). I. Ingestion, digestion and excretion. Physiol Comp Oecol 1: $110-128$

Wehrl M, Steinert M, Hentschel U (2007) Bacterial uptake by the marine sponge Aplysina aerophoba. Microb Ecol 53: 355-365

- Weissenfels N (1975) Bau und Funktion des Süßwasserschwamms Ephydatia fluviatilis L. (Porifera). II. Anmerkungen zum Körperbau. Zoomorphology 81:241-256.

> Weissenfels N (1976) Bau und Funktion des Süßwasserschwamms Ephydatia fluviatilis L. (Porifera). III. Nahrungsaufnahme, Verdauung und Defäkation. Zoomorphology 85:73-88

Willenz PB, Van de Vyver G (1984) Ultrastructural localization of lysosomal digestion in the fresh water sponge Ephydatia fluviatilis. J Ultrastruct Res 87:13-22

> Yahel G, Eerkes-Medrano DI, Leys SP (2006) Size dependent selective filtration of ultraplankton by hexactinellid glass sponges. Aquat Microb Ecol 45:181-194

Submitted: July 8, 2009; Accepted: November 9, 2009

Proofs received from author(s): March 1, 2010 